\title{
Effect of HPV 16 E6 Oncoprotein Variants on the Alterations of the Proteome of C33A Cells
}

\author{
OLGA LILIA GARIBAY-CERDENARES ${ }^{1,2}$, LUZ VICTORIA SÁNCHEZ-MEZA ${ }^{1}$, \\ SERGIO ENCARNACIÓN-GUEVARA ${ }^{3}$, MAGDALENA HERNÁNDEZ-ORTÍZ ${ }^{3}$, \\ GABRIEL MARTÍNEZ-BATALLAR ${ }^{3}$, FRANCISCO ISRAEL TORRES-ROJAS ${ }^{1}$, \\ MIGUEL ÁNGEL MENDOZA-CATALÁN ${ }^{1}$, OSCAR DEL MORAL-HERNÁNDEZ ${ }^{1}$, \\ MARCO ANTONIO LEYVA-VÁZQUEZ ${ }^{1}$ and BERENICE ILLADES-AGUIAR ${ }^{1}$ \\ ${ }^{1}$ Laboratorio de Biomedicina Molecular, Facultad de Ciencias Químico Biológicas, \\ Universidad Autónoma de Guerrero, Chilpancingo, México; \\ ${ }^{2}$ CONACyT- Universidad Autónoma de Guerrero, Chilpancingo, México; \\ ${ }^{3}$ Laboratorio de Proteómica, Centro de Ciencias Genómicas-UNAM, Cuernavaca, México
}

\begin{abstract}
Background/Aim: The E6 genotypic variants of $H P V 16$ identified in lesions of women with cervical cancer (CC) in Southern Mexico include the E-G350, AAa, AAc, EC188/G350, and E-A176/G350. Transcriptomic analysis cells transfected with those variants showed to induce differential expression of the host genes involved in the development of $C C$. The aim of this work was to understand how the over-expression of the E6 oncoprotein and its variants can induce molecular mechanisms that lead to more aggressive HPV 16 phenotypes in cervical cancer and which proteins could be associated with the process. Materials and Methods: Total extracts from C33A, C33A mock, C33A AAa, C33A E-C188/G350, C33A E-A176/G350, and C33A Eprototype cells were analyzed using $2 D$ electrophoresis, PDQuest software and mass spectrometry. Validation of results was performed through $q P C R$. Results: Statistically significant differential expression of 122 spots was detected, 12 of the identified proteins were associated with metabolism and metabolic programming. Out of these CCT8, ENO and ALDH1A were further validated. Conclusion: CCT8 and $A L D H 1 A$ were found to be over-expressed in C33A AAa and C33A E-A176/G350, compared to the E prototype. Both
\end{abstract}

This article is freely accessible online.

Correspondence to: Berenice Illades-Aguiar, Laboratorio de Biomedicina Molecular, Facultad de Ciencias Químico Biológicas, Universidad Autónoma de Guerrero, Av. Lázaro Cárdenas s/n, Ciudad Universitaria Sur. Chilpancingo, Gro, México. Tel/Fax +52 7474710901,e-mail: billades@uagro.mx

Key Words: HPV 16 E6 variants, 2D electrophoresis, proteomic analysis, cervical cancer. proteins could be associated with a most aggressive phenotype due to their relationship with metabolism, protein folding and stemness, mechanisms associated to E6 that could be useful in the design of new therapies.

Cervical cancer (CC) is the seventh most frequent cancer in women worldwide, with an estimated 604,127 new cases in 2020 , representing $3.1 \%$ of all female cancer deaths (1). More than $85 \%$ of the estimated deaths from cervical cancer every year occur in less developed regions (2). The American Cancer Society estimates 66570 new cases and 12940 deaths in 2021 in United States (3). In México, the Global Cancer Observatory reported 7,869 cases of cervical cancer in 2018 (4). It is well established that persistent infections caused by human papillomavirus (HPV) are the key etiological factors $(5,6)$. High-risk HPV type 16 (HPV 16) is the causal agent of more than half of $\mathrm{CC}$ in the world $(7,8)$.

The complete genome of HPV 16 is composed of 7,904 bp (9) that form a of double-stranded circular DNA containing 8 protein-coding genes (L1 and L2 that encode capsid proteins and E1, E2, E4, E5, E6, and E7 that encode proteins involved in replication, transcription, and transformation and a noncoding regulatory long control region (LCR) (10). The viral genes E6 and E7 of HPV 16 (11) are responsible for induction and maintenance of the transformed phenotype of cervical cancer cells specifically induced by abrogation of the mechanisms of apoptosis and cell cycle control (12-14). However, the E6 protein plays a role in mediating cell proliferation independently of E7 through its C-terminal PDZ-binding domain (15-17) and may contribute to development of metastatic tumors by disrupting normal cell-cell contacts $(18,19)$. HPV 16 has wellpreserved distinctive intratypic variants by geographical origin $(20,21)$ and phylogeny (22) classified into 4 lineages, 
including A (European-Asian, EAS), B (African 1, AF1), C (African 2, AF2), and D (North American/Asian American, NA/AA), and 9 sublineages, including A1, A2, A3 (E), A4 (As), B1 (Afr1a), B2 (Afr1b), D1 (NA), D2 (AA1), and D3 (AA2) $(22,23)$. Global distribution of the variants and risk of cervical cancer appear to be dependent on the population $(24,25)$. Our research group reported that the intratypical variants of HPV 16 E6, including E-G350, E-A176/G350, EC188/G350, AAa, and AAc, are the most common and have the highest oncogenic potential in the development of $\mathrm{CC}$ in southern Mexico (26). The effect of the overexpression of those HPV 16 E6 prototype and variants on the gene expression profiles showing a differential expression of the host genes involved in the development of CC (27). Recently, the 3D structures of the HPV 16 E6 oncoprotein and intratypical variants were performed, showing subtle changes in amino acid disorder probably associated with different interactions with target protein patterns (28). In this study, we evaluated the differential abundance of protein spots induced in the C33A cell line by overexpression of E6 variants using a $2 \mathrm{D}$ electrophoresis (2-DE)/MALDI-TOF strategy to predict variants of the protein that can be related to potential oncogenic risk and thereby provide information about the development and progression of malignant lesions generated by HPV 16.

\section{Materials and Methods}

Cell culture. C33A cells expressing the HPV 16 E6 gene variants AA-a, AA-c, E-A176/G350, E-C188/G350, and E-G350 and Eprototype (27) were grown at $37^{\circ} \mathrm{C}$ in the presence of $5 \% \mathrm{CO}_{2}$ in MEM supplemented with $10 \%$ fetal bovine serum (Gibco, Life Technologies, Gaithersburg, MD, USA), $100 \mathrm{U} / \mathrm{ml}$ penicillin, and $100 \mu \mathrm{g} / \mathrm{ml}$ streptomycin.

2-DE assays. Total protein extracts $(600 \mu \mathrm{g})$ were acheived according a protocol described by Toledo-Leyva et al., 2018 (29) and 2-DE was performed according to the protocols of Klose (30) and O'Farrell (31), $600 \mu \mathrm{g}$ (preparative gels) of total protein extract was separated through $12 \%$ acrylamide gel under denaturing conditions. Three replicates for each condition were assayed. Gels were fixed, stained with colloidal Coomassie blue (Amresco, Cat. No. 6104-58-1), neutralized and washed with $25 \%$ methanol in 0.1 $\mathrm{M}$ Tris- $\mathrm{HCl}, \mathrm{pH}$ 6.5. The gels were scanned at GS-800 (Bio-Rad Hercules, GS-800, CA, USA).

Data analysis of 2-DE, mass spectrometry (MALDI-TOF) and protein identification. Digital images were analyzed and compared using the PDQuest software version 8.0.1. Selected spots identified were manually excised, and proteins were reduced, alkylated and digested to generate the peptides. Mass spectrometry protocol was perfom according Higareda-Almazan et al., 2011 (32), using a MALDI-TOF system (matrix-assisted laser desorption/ionization-time of flight, Autoflex Bruker Daltonics, Billerica, MA, USA). The Proteineer SP and SPII systems (Bruker Daltonics, Bremen, Germany; SP control 3.1.48.0v software) were used. The Bruker Daltonics Autoflex system was configured in the delayed extraction and reflectron mode. The obtained $\mathrm{m} / \mathrm{z}$ values were compared with the protein sequences of the Homo sapiens databases of NCBI using Mascot 2.2 following parameters: Taxon-Human, mass tolerance of up to $200 \mathrm{ppm}$, one miss-cleavage allowed, and as the fixed modification carbamidomethyl and oxidation of methionine as the variable modification.

Bioinformatics analysis. To determine cellular processes associated with identified proteins, UniProt (EMBL-EBI) (www.uniprot.org/) (33), IntAct (EMBL-EBI) (http://www.ebi.ac.uk/intact/) (34), Reactome (EMBL-EBI) (http://www.reactome.org/) (35), and GeneCards (http://www.genecards.org/) (36) were used. The search parameters were as follows: Homo sapiens species, function, name, subcellular location, sequence(s), interaction, signaling pathways, and information. Selected proteins were subjected to analysis in Cytoscape (http://www.cytoscape.org/) (37) and STRING (https://string-db.org/) (38), which is a very useful tool for the analysis of networks of molecular interactions between proteins. A search in The Human Protein Atlas (http://www.proteinatlas.org/) (39) was used to determine the levels of protein expression in cell lines, normal human tissues, and various types of cancer.

Real-time quantitative PCR. Total RNA was isolated from cell cultures at $60 \%$ confluence using TRIzol (Thermo Fisher Scientific, Waltham, MA, USA) according to the supplier's instructions. The RNA was treated with DNAse I to eliminate residual DNA, and reverse transcription was performed using oligo(dT). cDNA synthesis was carried out using SuperScriptIII reverse transcriptase (Thermo Fisher Scientific) following the manufacturer's instructions. Amplification of the genes of interest was carried out from $100 \mathrm{ng}$ of cDNA using $\mathrm{TaqMan}^{\mathrm{TM}}$ gene expression master mix (Thermo Fisher Scientific) and specific probes for ALDH1A1 (Hs00946916_m1), CCT8 (Hs00607229_mH), ENO1 (Hs00361415_m1), and GAPDH (Hs99999905_m1). The experiments were performed in triplicate on a PikoReal $^{\mathrm{TM}}$ real-time PCR system (Thermo Fisher Scientific), and the endogenous GAPDH gene was used as a control. The relative expression was calculated using the $2^{-\Delta \Delta \mathrm{Ct}}$ method, and the means for each group are reported.

Statistical analysis. Statistical analyses of the data were performed using SPSS v.20.0 (SPSS, Inc., Chicago, IL, USA) and GraphPad Prism software (v.5.0; GraphPad Software, Inc., La Jolla, CA, USA). The Mann Whitney test was used for the comparison of the differences in mRNA expression levels between the groups $(p<0.05)$.

\section{Results}

Protein identification. The C33A cervical cancer cell line derived from a patient with cervical carcinoma without HPV infection has been widely used in our working group as an in vitro model to analyze the molecular and functional effects of the overexpression of the HPV 16 E6 oncoprotein and its variants (AA-a, E-A176/G350, E-C188/G350, E-G350) in comparison with E-Prototype. To evaluate the changes in the proteome of cells induced by overexpression of the E6 oncoprotein and its variants, a screening strategy was established at three levels. At the first level, the basal phenotypic expression of the C33A cells was obtained 


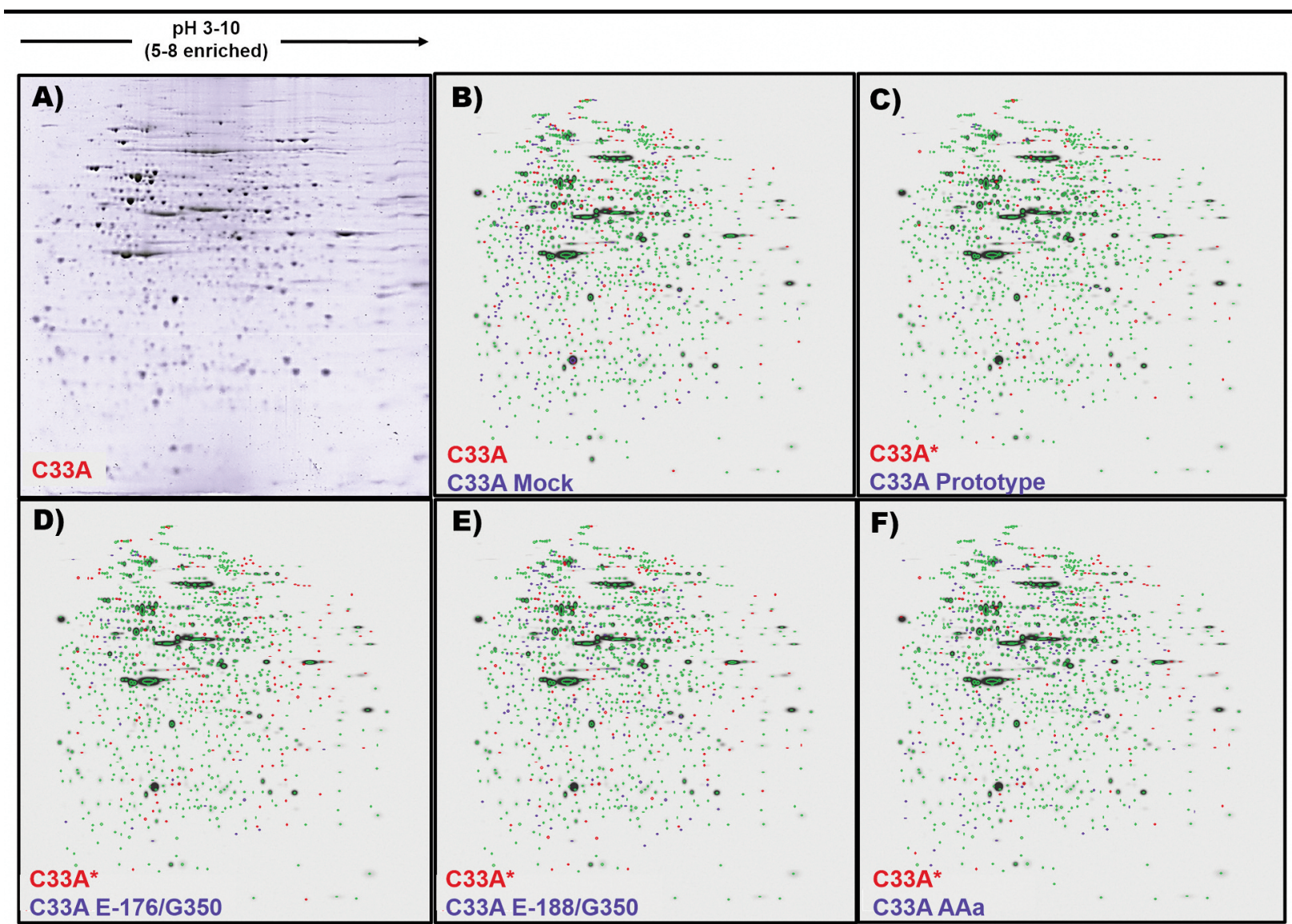

Figure 1.2D protein maps of C33A cells. Totals proteins were extracted and separated by two-dimensional gel electrophoresis $(2 \mathrm{D}$ PAGE). In isoelectric focusing, $500 \mu \mathrm{g}$ of protein were loaded and separated at linear pH range of 3-10 (4-8 enrichment), the ampholyte enrichment range of 4-8 improves the resolution of proteins in these regions. The location of the proteins in the $2 D$ gels that are expressed, are placed between a weight range of 20 to $250 \mathrm{kDa}$ (Gel stained with Coomassie Blue G-250). (A) C33A cells protein expression profile. (B-F). Master gel of protein pattern comparison between the C33A* cells and C33A E-Prototype, C33A E-A176/G350, C33A E-C188/G350 and C33 AAa. The proteins that are common to both cell lines are shown in green, proteins that belong only to $C 33 A^{*}$ are shown in red and proteins that are only expressed in C33A* are shown in blue.

(Figure 1A) and compared to the protein expression profile in the C33A mock cells (Figure 1B), this first analysis allowed to detect the overexpression of proteins not associated to the basal phenotype that could have been influenced by some cytotoxicity derived from the insertion process of the empty vector and thus, to generate the proteomic profile of $\mathrm{C} 33 \mathrm{~A} *$ expression pattern. At the second level, the expression profile was compared to the expression profiles of $\mathrm{C} 33 \mathrm{~A}$ cells overexpressing the prototype and E-A176/G350, E-C188/G350, and AAa variants. Finally, at the third level, validation was performed by comparison of the gene expression in $\mathrm{C} 33 \mathrm{~A}$ cells expressing the E6 prototype versus $\mathrm{C} 33 \mathrm{~A}$ cells expressing each variant as described previously (Figure 1C-F).

After 2-DE gels from biological replicates have been digitized, the comparison of the conditions was performed using the master gel, which is a digital image generated by the PD-Quest Software, representing the map of statistically significant spots derived from the average of the comparative replicates between two conditions, highlighting in two colors the differential spots between conditions. Those comparisons including C33A prototype, C33A AAa, C33A E-C188/G350, and C33A E-A176/G350 against C33A* cells. This analysis detected groups of differentially expressed proteins with a statistical significance of $p \leq 0.01$ (Figure 2). Fifteen of the detected spots were detected under all conditions and were selected for identification by mass spectrometry (MALDITOF/TOF) using the MASCOT v2.2 database based on the abundance of the spots, twelve of them were identified and annotated: id; theoretical molecular weight and isoelectric point were acquired from Uniprot (33). The identified proteins included T-complex protein 1 subunit theta (CCT8), 

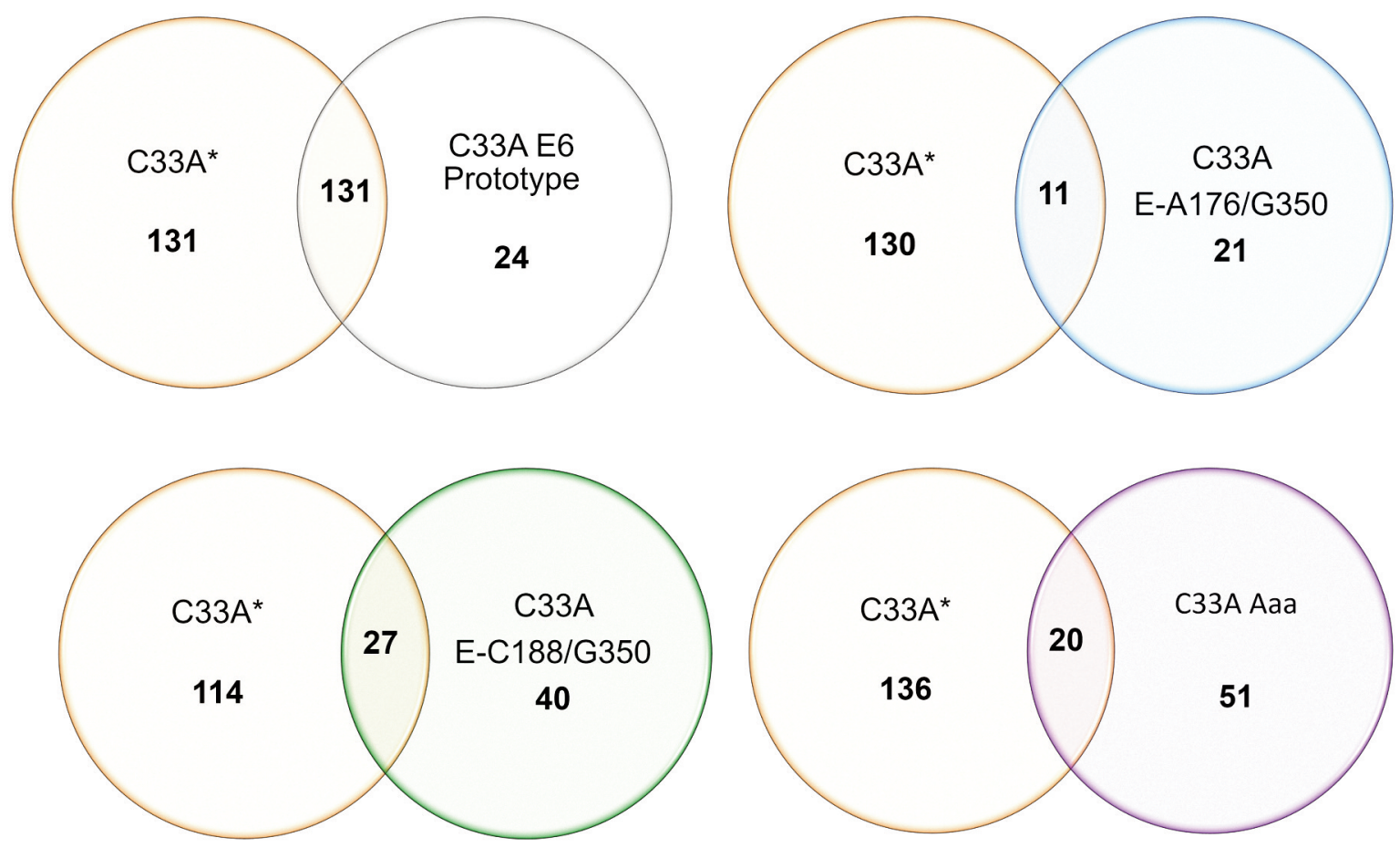

Figure 2. Comparative analysis strategy. The number of differentially expressed proteins between E6 of prototype HPV16, C33A E-A176/G350, C33A E-C188/G350 and C33 AAa, compared to C33A*. Using the PDQuest software and by employing Venn diagrams, the comparison in the expression of differentially expressed proteins between the different cell lines is shown in Table I. Identification of proteins by mass spectrometry was performed according to the Mascot software.

retinal dehydrogenase 1 (ALDH1A1), alpha-enolase (ENO), potassium voltage-gated channel subfamily $\mathrm{H}$ member 1 (KCNH1), serine/threonine-protein phosphatase 2A $65 \mathrm{kDa}$ regulatory subunit A alpha isoform (PPP2R1A), zinc finger protein 554 (ZN554), glucose-6-phosphate 1-dehydrogenase (G6PD), armadillo repeat-containing $\mathrm{X}$-linked protein 1 (ARMX1), glyoxylate reductase/hydroxypyruvate reductase (GRHPR), carnitine O-palmitoyltransferase 1 (CPT1A), DNA-binding domain-containing protein 1 (CENP), and zinc finger protein 93 (ZNF93) (Table I).

In silico analysis of protein functions. To identify the functions of KCNH1, PPP2R1A, CCT8, ALDH1A1, ZN554, ENOA, G6PD, ARMX1, GRHPR, CPT1A, CENP, and ZNF93, an in silico analysis was performed using the pathway enrichment analysis by Gene Ontology. All proteins were associated with various molecular functions, such as catalytic activity, binding, transcriptional regulation, and transport function (Figure 3A); the interaction analysis using the STRING database grouping in molecular functions showed at least three specific biological processes, such as metabolism (including metabolism of carbohydrates in the case of PPP2R1A, CCT8, ENOA, G6PD, and GRHPR), metabolic programming (including ALDH1A1 and CPT1A mainly associated with cancer stem cells) and signaling pathways (including KCNH1, ZN554, ARMX1, and ZNF93) (Figure 3B). General analysis indicated that $60 \%$ of proteins were related to protein metabolic processes, generation of energy, precursor metabolites, and processes that involve cancer cell transformation.

Validation of differential gene expression. Differential expression of identified proteins was validated by real-time PCR in all the previously extensively investigated variants by our work group due to their high incidence in the southern population, including E6 prototype and E-G350, EA176/G350, E-C188/G350, AAa, and AAc variants. The results showed a decrease in the expression of the ALDH1A gene in all cell lines compared to $\mathrm{C} 33 \mathrm{~A} *$; the lowest expression was observed in C33A E-A176/G350 and C33A AAa compared to that in cells expressing all the remaining E6 oncoprotein variants (Figure 4A). CCT8 expression was decreased in the C33A E-A176/G350, C33A prototype, and C33A AAa variants (Figure 4B). ENO expression was not significantly changed between the variants (Figure 4C). Comparison of the changes in protein expression between the E-prototype and E6 variants showed that ALDHA1 


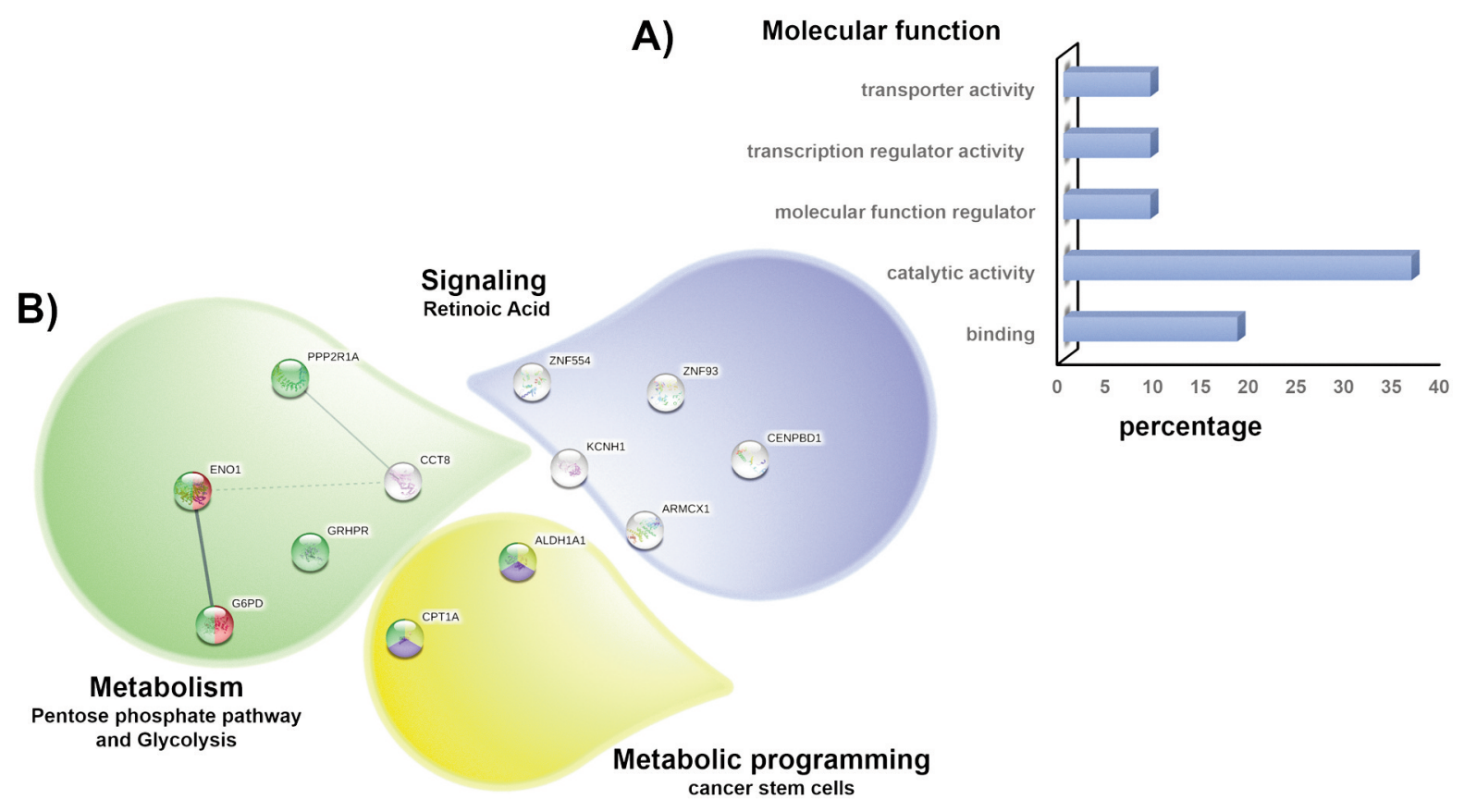

Figure 3. Interactome of differentially expressed proteins among E6 oncoprotein variants. Through the STRING database the interaction analysis of the 12 identified proteins is shown, each node represents the protein under analysis and the thickness of the connectors correlates with the evidence of their functional association. According to the Reactome database, the proteins are mainly associated with metabolic pathways (carbohydrates and retinoic acid) and metabolic reprogramming such as stemness.

Table I. Identification of proteins by mass spectrometry according to Mascot software.

\begin{tabular}{|c|c|c|c|c|c|c|c|c|}
\hline No. & $\begin{array}{c}\text { ID } \\
\text { SPOT }^{\$}\end{array}$ & Gene & Name & $\begin{array}{l}\text { Uniprot } \\
\text { ID }\end{array}$ & $\begin{array}{c}\mathrm{Mw}^{* *} \\
(\mathrm{kDa})\end{array}$ & $\mathrm{IP}^{\#}$ & $\begin{array}{c}\text { Coverage } \\
\%\end{array}$ & $\begin{array}{c}\text { Regulation } \\
\text { folds } \\
\text { against } \\
\text { C33A* }\end{array}$ \\
\hline 1 & V24 & CPT1A & Carnitine O-palmitoyltransferase 1 & P50416 & 89007 & 8.85 & 12 & +1.17 \\
\hline 2 & $\mathrm{~V} 20$ & CENP & CENPB DNA-binding domain-containing protein 1 & B2RD01 & 21115 & 6.54 & 28 & +0.61 \\
\hline 3 & $\mathrm{~V} 21$ & ZNF93 & Zinc finger protein 93 & P35789 & 73129 & 9.40 & 12 & +3.56 \\
\hline 4 & V30 & KCNH1 & $\begin{array}{c}\text { Potassium voltage-gated channel } \\
\text { subfamily } \mathrm{H} \text { member } 1\end{array}$ & O95259 & 112454 & 7.52 & 10 & +1.67 \\
\hline 5 & V50 & PPP2R1A & $\begin{array}{l}\text { Serine/threonine-protein phosphatase } 2 \mathrm{~A} \\
65 \mathrm{kDa} \text { regulatory subunit } \mathrm{A} \text { alpha isoform }\end{array}$ & P30153 & 66079 & 5.0 & 12 & +1.93 \\
\hline 6 & V51 & CCT8 & T-complex protein 1 subunit theta & P50990 & 60163 & 5.42 & 26 & +1.30 \\
\hline 7 & V56 & ALDH1A1 & Retinal dehydrogenase 1 & P00352 & 55454 & 6.30 & 28 & +2.01 \\
\hline 8 & V57 & ZN554 & Zinc finger protein 554 & Q86TJ5 & 61935 & 7.56 & 16 & +0.90 \\
\hline 9 & V59 & ENOA & Alpha-enolase & P06733 & 47487 & 7.01 & 36 & +1.52 \\
\hline 10 & V72 & G6PD & Glucose-6-phosphate 1-dehydrogenase & P11413 & 59675 & 6.39 & 27 & +3.36 \\
\hline 11 & V80 & ARMX1 & Armadillo repeat-containing X-linked protein 1 & Q9P291 & 49730 & 9.32 & 11 & +0.61 \\
\hline 12 & V84 & GRHPR & Glyoxylate reductase/hydroxypyruvate reductase & Q9UBQ7 & 36052 & 7.01 & 16 & +0.55 \\
\hline
\end{tabular}

The peptide profile of the "spots" was analyzed by MALDI-TOF/TOF and identified with the Mascot software. $\$$ ID SPOT indicates the protein codes for MALDI TOF identification.**Mw: Theorical molecular wegth (kilodaltons). ${ }^{*}$ IP: Theorical isoelectric point.

expression was decreased only in C33A E-A176/G350 and increased in C33A E-C188/G350 and G-350 variants. The expression of the CCT8 gene was decreased in C33A EA176/G350 and C33A AAa variants (Figure 4D).

\section{Discussion}

HPV 16 is an etiological factor in cervical cancer $(5,40)$ due the expression of E6 and E7 oncoproteins that enhance the cell 


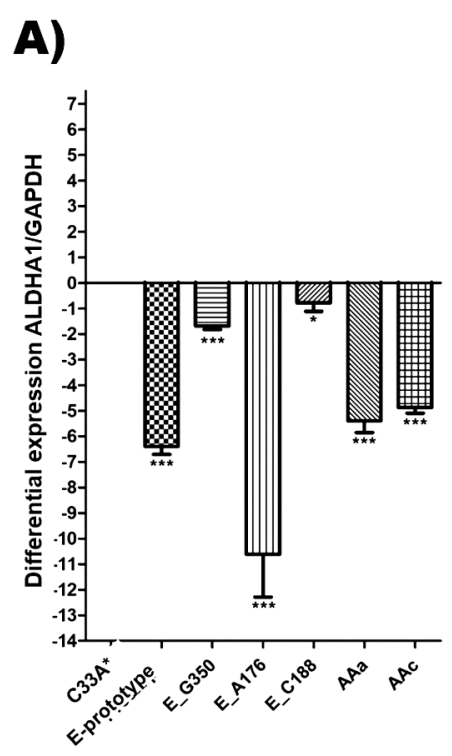

B)

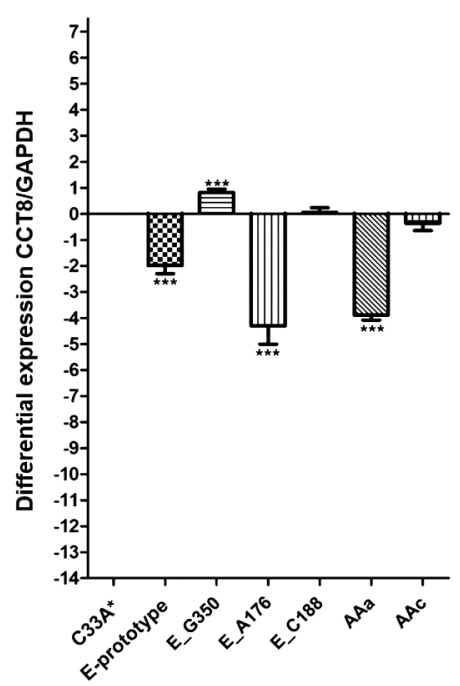

C)

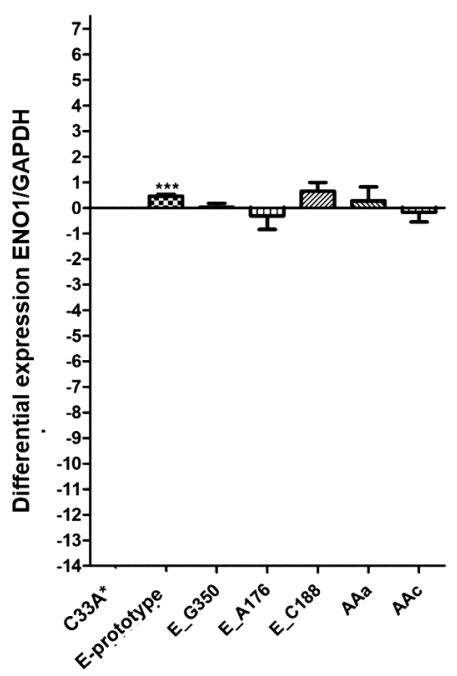

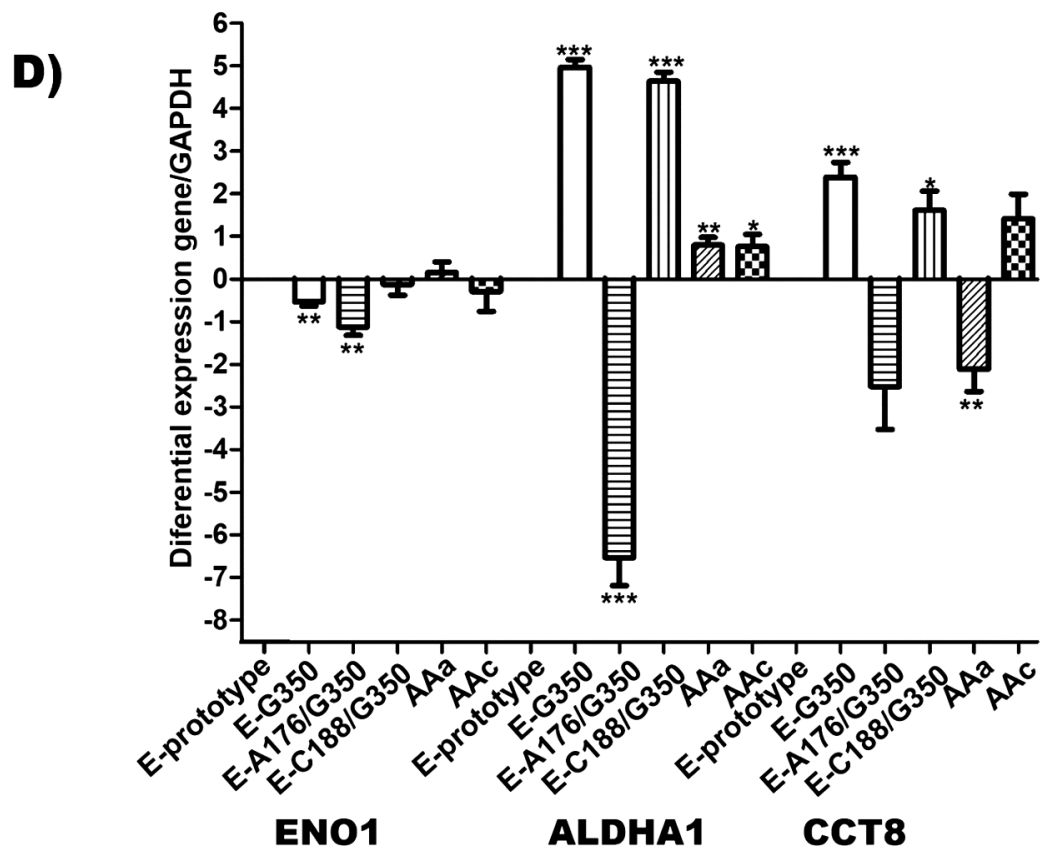

Figure 4. Validation of differentially expressed genes in C33A* in comparison with E6 oncoprotein and its variants. (A-C) Relative expression levels of genes ALDH1A, CCT8 and ENO1 in C33A* cells in comparison with C33A E-Prototype, C33A E-A176/G350, C33A E-C188/G350, C33 AAa and C33 AAc. (D) Relative expression levels of $m R N A$ in C33A E-prototype cells in comparison with E6 variants. Values are expressed as mean \pm SEM. Significant differences are considered with $p \leq 0.05$. Each gene-specific cDNA was quantified in triplicate and $m R N A$ ratios relative to the housekeeping gene GAPDH were calculated. The relative quantification of mRNA was analyzed using method 2- $\Delta \Delta C t$.

cycle in the upper epithelial layers of the cervix (41-43), which, in some cases, can stimulate the proliferation of infected basal cells and eventually lead to neoplasia (12). These viral proteins are able to bind and inactivate the tumor suppressor genes such as p53 and retinoblastoma $(\mathrm{Rb})$, among others, resulting in increased survival and proliferation to induce immortalization of cervical cells $(44,45)$.

Our research group analyzed the frequency of the intratypic variants of the E6 gene of HPV 16, showing that E-G350, E-A176/G350, E-C188/G350, AAa and AAc, are 
the most prevalent in the State of Guerrero and demonstrating that infection by the AAa variant presented the strongest association with the risk of developing CC (26). Additionally, those variants were analyzed by transcriptomics through overexpression in the C33A cells showing differences in genes mainly associated with tumor progression (27). By comparing the protein profiles of $\mathrm{C} 33 \mathrm{~A}$ cells overexpressing the prototype E6 oncoprotein and its variants with respect to $\mathrm{C} 33 \mathrm{~A}^{*}, 15$ highly abundant proteins were selected in the gel, of which 12 were identified with a percentage of coverage greater than $10 \%$. ALDH1A1 was found differentially expressed in both the transcriptomics results previously described and in the proteomic analyses of this working group. This differentially expressed gene was also detected by Prokopczyk et al. using the Codelink Human Whole Genome Bioarray system after treatment of HPV 16-immortalized human ectocervical cells with a nicotine-derived carcinogen (46) and by Ganguly et al. using an Affymetrix gene chip array to compare gene expression profiles between the cells expressing E6 protein from highrisk HPV 18 and low-risk HPV 11 (47).

Aldehyde dehydrogenase (ALDH1A1) it is an enzyme involved in oxidation of a variety of intracellular aldehydes to carboxylic acids (48), is widely distributed in tissues and at the subcellular level, can be located in the cytoplasm, mitochondria, and endoplasmic reticulum (49). This enzyme has been identified in different tumors, including breast (50), colorectal (51), ovarian cancer (52) and melanoma (53); also ALDH1A1 has been correlated with tumor size, high histological grade, and advanced TNM stage (50). The members of the ALDH family play important roles in a variety of biological activities in cancer stem cells (48), including oxidative stress response (54), differentiation (55), and drug resistance (56). ALDH regulates stem cell proliferation and differentiation $(57,58)$. ALDH1A1 plays an important role in the regulation of stemness in ovarian cancer $(59,60)$.

Analysis of global gene expression profiles influenced by high-risk (HPV 18) and low-risk (HPV 11) E6 oncoproteins by microarray and qRT-PCR identified ALDH1A1 as one of the genes with decreased expression in HPV 18 and overexpression in HPV 11 suggesting potential use of ALDH1A 1 as a biomarker for the diagnosis and progression of esophageal cancer and as a therapeutic target (47). ALDH1A has not been analyzed in E6 overexpression; however, our results based on the comparison with other variants showed that ALDH1A is one of the most overexpressed proteins in HPV 16 E6 E-A176/G350, and comparison with the E-prototype indicated that ALDH1A expression is decreased. However, even if the genotypic variants had few amino acid changes versus the E6 prototype, they are involved in changes in the gene and protein expression profiles and may be involved in differences in tumor progression; however, these suggestions require additional studies.

Human embryonic stem cells can proliferate and replicate indefinitely, while maintaining their undifferentiated state (61). Human pluripotent stem cells show enhanced assembly of the TRiC/CCT complex, a chaperone that facilitates the folding of $10 \%$ of the proteome (62). The CCT8 gene encodes a component of a type II chaperonin (63), which forms a large cytosolic double-ring oligomeric complex that contributes to protein folding (64). In the presence of ATP, the primary substrates for CCT may include diverse proteins (65), such as cytoskeleton proteins like actin and tubulin (66) which contain motifs common to the other CCT subunits involved in ATPase activity (67). The expression of CCTs early in the embryonic process suggests that they may be critical for cell cycle regulation and maintenance of pluripotency (68). CCT8 has been detected in several types of cancers, such as esophageal squamous cell carcinoma (69), hepatocellular carcinoma (70), and B-cell nonHodgkin's lymphoma (71). Wurlitzer et al. performed a mass spectrometric comparison of HPV-positive and HPV-negative oropharyngeal tumors and identified differentially expressed proteins, such as CCT8, in HPV-positive samples reflecting enhanced migration and invasion (72). Results show an underexpression of the ALDHA1A and CCT8 genes in the E-A176/G350 and AAa variants when compared to the prototype, however, at the protein level they showed the highest levels of expression (Table I). Although the gene and protein expression data do not correlate, the AAa variant has been shown to be associated with an increased risk of tumor progression, thus some other molecular regulatory mechanism may be involved.

Gene lists obtained in the present study included some upand down-regulated genes compared to the results published by other authors; therefore, further investigation is needed to validate selected biomarkers. However, all proteins identified in cells expressing HPV variants are clearly associated with tumor progression, induction of mortality, and development of stemness.

\section{Conclusion}

Although HPV 16 has been associated with cervical cancer, only a percentage of precursor lesions progress to invasive cervical cancer, which implies the involvement of molecular mechanisms associated with the virus. The presence of intratypic variants in the E6 gene that result in changes in its oncoprotein structure are beginning to be studied, and it has been observed that Asian-American variants are mostly associated with the progression of precursor lesions to carcinogenesis. ALDHA1 and CCT8 are differentially upregulated in cells expressing E6 oncoprotein variants EA176/G350 and AAa, and these proteins are strongly 
associated with tumor progression, induction of immortality, and development of stemness. Thus, further analysis is needed to explore their potential as biomarkers in cervical cancer progression; these proteins are mainly associated with HPV 16 E6 variants, which are involved in tumor progression.

\section{Conflicts of Interest}

The Authors declare that they have no competing interests.

\section{Authors' Contributions}

This work was carried out through the collaboration of all the authors. OLGC, LVSM. MHO, GMB and ITR were responsible of the experiments design. OMH, LVSM, SMEG, MHO, GMB, participated in 2D and image analysis. OLGC, SMEG, MHO. MAMC, MALV and BIA participated in the results interpretation and drafting of the manuscript. OLGC and BIA wrote the final version of the manuscript. All Authors have read and approved the final manuscript.

\section{Acknowledgements}

This work was partially supported by grants from Basic Science 2016 (288612) from CONACyT. Sánchez-Meza LV was a recipient of a CONACyT fellowship (700387).

\section{References}

1 International Agency for Research of Cancer: Estimated agestandardized incidence and mortality rates (world) in 2020, worldwide, both sexes, all ages (2021). Available at: https:// gco.iarc.fr/today/online-analys is-multi-bars?v=2020 $\&$ mode $=$ cancer $\&$ mode_population $=$ countries $\&$ population $=900 \&$ populations $=900 \&$ key $=$ asr $\&$ sex $=0 \&$ cancer $=39 \&$ type $=0 \&$ statistic $=5 \&$ prevalence $=0 \&$ population_group $=0 \&$ ages_group $\% 5 \mathrm{~B} \% 5 \mathrm{D}=$ 0\&ages_group $\% 5 \mathrm{~B} \% 5 \mathrm{D}=17 \& \mathrm{nb}$ _items $=10 \&$ group_cancer $=1 \& \mathrm{i}$ nclude_nmsc $=1 \&$ include_nmsc_other $=1 \&$ type_multiple $=\% 257 \mathrm{~B}$ $\% 2522$ inc $\% 2522 \% 253$ Atrue $\% 252 \mathrm{C} \% 2522$ mort $\% 2522 \% 253$ Atru e $\% 252 \mathrm{C} \% 2522$ prev\%2522\%253Afalse $\% 257 \mathrm{D} \&$ orientation=hori zontal\&type_sort=0\&type_nb_items $=\% 257 \mathrm{~B} \% 2522$ top $\% 2522 \%$ 253Atrue $\% 252 \mathrm{C} \% 2522$ bottom\%2522\%253Afalse \% 257D [Last accessed on February 16, 2021]

2 Global burden of cervical cancer (2021). Available at: https://www.who.int/news-room/fact-sheets/detail/humanpapillomavirus-(hpv)-and-cervical-cancer [Last accessed on February 6, 2021]

3 Siegel R, Miller K, Fuchs H and Jemal A: Cancer statistics, 2021. CA: A Cancer Journal for Clinicians 71(1): 7-33, 2021. DOI: $10.3322 /$ caac. 21654

4 Bray F, Ferlay J, Soerjomataram I, Siegel R, Torre L and Jemal A: Global cancer statistics 2018: GLOBOCAN estimates of incidence and mortality worldwide for 36 cancers in 185 countries. CA: A Cancer Journal for Clinicians 68(6): 394-424, 2019. DOI: $10.3322 /$ caac. 21492

5 Bosch FX, Lorincz A, Muñoz N, Meijer CJ and Shah KV: The causal relation between human papillomavirus and cervical cancer. J Clin Pathol 55(4): 244-265, 2002. PMID: 11919208. DOI: $10.1136 /$ jcp. 55.4 .244
6 Burd EM: Human papillomavirus and cervical cancer. Clin Microbiol Rev 16(1): 1-17, 2003. PMID: 12525422. DOI: 10.1128/cmr.16.1.1-17.2003

7 Zur hausen H: Papillomaviruses in the causation of human cancers - a brief historical account. Virology 384(2): 260-265, 2020. DOI: $10.1016 /$ j.virol.2008.11.046

8 Harro CD, Pang YY, Roden RB, Hildesheim A, Wang Z, Reynolds MJ, Mast TC, Robinson R, Murphy BR, Karron RA, Dillner J, Schiller JT and Lowy DR: Safety and immunogenicity trial in adult volunteers of a human papillomavirus $16 \mathrm{~L} 1$ viruslike particle vaccine. J Natl Cancer Inst 93(4): 284-292, 2001. PMID: 11181775. DOI: 10.1093/jnci/93.4.284

9 Seedorf K, Krämmer G, Dürst M, Suhai S and Röwekamp WG: Human papillomavirus type 16 DNA sequence. Virology 145(1): 181-185, 1985. PMID: 2990099. DOI: 10.1016/0042-6822(85) 90214-4

10 Bernard HU, Calleja-Macias IE and Dunn ST: Genome variation of human papillomavirus types: phylogenetic and medical implications. Int J Cancer 118(5): 1071-1076, 2006. PMID: 16331617. DOI: $10.1002 / \mathrm{ijc} .21655$

11 Wlazlo AP, Giles-Davis W, Clements A, Struble G, Marmorstein $\mathrm{R}$ and Ertl HC: Generation and characterization of monoclonal antibodies against the E6 and E7 oncoproteins of HPV. Hybridoma 20(4): 257-263, 2001. PMID: 11604112. DOI: $10.1089 / 027245701753179848$

12 Doorbar J, Egawa N, Griffin H, Kranjec C and Murakami I: Human papillomavirus molecular biology and disease association. Rev Med Virol 25(Suppl 1): 2-23, 2015. PMID: 25752814. DOI: $10.1002 / \mathrm{rmv} .1822$

13 Münger K and Howley PM: Human papillomavirus immortalization and transformation functions. Virus Res 89(2): 213-228, 2002. PMID: 12445661. DOI: 10.1016/s0168-1702(02)00190-9

14 Spangle JM and Münger K: The human papillomavirus type 16 E6 oncoprotein activates mTORC1 signaling and increases protein synthesis. J Virol 84(18): 9398-9407, 2010. PMID: 20631133. DOI: 10.1128/JVI.00974-10

15 Yoshimatsu Y, Nakahara T, Tanaka K, Inagawa Y, NarisawaSaito M, Yugawa T, Ohno SI, Fujita M, Nakagama H and Kiyono T: Roles of the PDZ-binding motif of HPV 16 E6 protein in oncogenic transformation of human cervical keratinocytes. Cancer Sci 108(7): 1303-1309, 2017. PMID: 28440909. DOI: $10.1111 /$ cas. 13264

16 Thomas M, Laura R, Hepner K, Guccione E, Sawyers C, Lasky L and Banks L: Oncogenic human papillomavirus E6 proteins target the MAGI-2 and MAGI-3 proteins for degradation. Oncogene 21(33): 5088-5096, 2002. PMID: 12140759. DOI: 10.1038/sj.onc. 1205668

17 Ganti K, Broniarczyk J, Manoubi W, Massimi P, Mittal S, Pim D, Szalmas A, Thatte J, Thomas M, Tomaić V and Banks L: The human papillomavirus E6 PDZ binding motif: From life cycle to malignancy. Viruses 7(7): 3530-3551, 2015. PMID: 26147797. DOI: $10.3390 / \mathrm{v} 7072785$

18 Nguyen ML, Nguyen MM, Lee D, Griep AE and Lambert PF: The PDZ ligand domain of the human papillomavirus type 16 E6 protein is required for E6's induction of epithelial hyperplasia in vivo. J Virol 77(12): 6957-6964, 2003. PMID: 12768014. DOI: $10.1128 /$ jvi.77.12.6957-6964.2003

19 Nguyen MM, Nguyen ML, Caruana G, Bernstein A, Lambert PF and Griep AE: Requirement of PDZ-containing proteins for cell cycle regulation and differentiation in the mouse lens epithelium. 
Mol Cell Biol 23(24): 8970-8981, 2003. PMID: 14645510. DOI: 10.1128/mcb.23.24.8970-8981.2003

20 Calleja-Macias IE, Kalantari M, Huh J, Ortiz-Lopez R, RojasMartinez A, Gonzalez-Guerrero JF, Williamson AL, Hagmar B, Wiley DJ, Villarreal L, Bernard HU and Barrera-Saldaña HA: Genomic diversity of human papillomavirus-16, 18, 31, and 35 isolates in a Mexican population and relationship to European, African, and Native American variants. Virology 319(2): 315323, 2004. PMID: 14980491. DOI: 10.1016/j.virol.2003.11.009

21 Nicolás-Párraga S, Gandini C, Pimenoff VN, Alemany L, de Sanjosé S, Xavier Bosch F, Bravo IG and RIS HPV TT and HPV VVAP study groups.: HPV16 variants distribution in invasive cancers of the cervix, vulva, vagina, penis, and anus. Cancer Med 5(10): 2909-2919, 2016. PMID: 27654117. DOI: $10.1002 / \mathrm{cam} 4.870$

22 Burk RD, Harari A and Chen Z: Human papillomavirus genome variants. Virology 445(1-2): 232-243, 2013. PMID: 23998342. DOI: 10.1016/j.virol.2013.07.018

23 Cornet I, Gheit T, Franceschi S, Vignat J, Burk RD, Sylla BS, Tommasino M, Clifford GM and IARC HPV Variant Study Group.: Human papillomavirus type 16 genetic variants: phylogeny and classification based on E6 and LCR. J Virol 86(12): 68556861, 2012. PMID: 22491459. DOI: 10.1128/JVI.00483-12

24 Cornet I, Gheit T, Iannacone MR, Vignat J, Sylla BS, Del Mistro A, Franceschi S, Tommasino $M$ and Clifford GM: HPV16 genetic variation and the development of cervical cancer worldwide. $\mathrm{Br} \mathrm{J}$ Cancer 108(1): 240-244, 2013. PMID: 23169278. DOI: $10.1038 /$ bjc.2012.508

25 Tornesello ML, Losito S, Benincasa G, Fulciniti F, Botti G, Greggi S, Buonaguro L and Buonaguro FM: Human papillomavirus (HPV) genotypes and HPV16 variants and risk of adenocarcinoma and squamous cell carcinoma of the cervix. Gynecol Oncol 121(1): 32-42, 2011. PMID: 21211829. DOI: 10.1016/j.ygyno.2010.12.005

26 Ortiz-Ortiz J, Alarcón-Romero Ldel C, Jiménez-López MA, Garzón-Barrientos VH, Calleja-Macías I, Barrera-Saldaña HA, Leyva-Vázquez MA and Illades-Aguiar B: Association of human papillomavirus 16 E6 variants with cervical carcinoma and precursor lesions in women from Southern Mexico. Virol J 12: 29, 2015. PMID: 25889023. DOI: 10.1186/s12985-015-0242-3

27 Zacapala-Gómez AE, Del Moral-Hernández O, VillegasSepúlveda N, Hidalgo-Miranda A, Romero-Córdoba SL, Beltrán-Anaya FO, Leyva-Vázquez MA, Alarcón-Romero Ldel $\mathrm{C}$ and Illades-Aguiar B: Changes in global gene expression profiles induced by HPV 16 E6 oncoprotein variants in cervical carcinoma C33-A cells. Virology 488: 187-195, 2016. PMID: 26655236. DOI: 10.1016/j.virol.2015.11.017

28 Rodríguez-Ruiz HA, Garibay-Cerdenares OL, Illades-Aguiar B, Montaño S, Jiang X and Leyva-Vázquez MA: In silico prediction of structural changes in human papillomavirus type 16 (HPV16) E6 oncoprotein and its variants. BMC Mol Cell Biol 20(1): 35 , 2019. PMID: 31426742. DOI: 10.1186/s12860-019-0217-0

29 Toledo-Leyva A, Villegas-Pineda JC, Encarnación-Guevara S, Gallardo-Rincón D and Talamás-Rohana P: Effect of ovarian cancer ascites on SKOV-3 cells proteome: New proteins associated with aggressive phenotype in epithelial ovarian cancer. Proteome Sci 16: 3, 2018. PMID: 29456457. DOI: 10.1186/s12953-018-0133-9

30 Klose J and Kobalz U: Two-dimensional electrophoresis of proteins: An updated protocol and implications for a functional analysis of the genome. Electrophoresis 16(6): 1034-1059, 1995. PMID: 7498127. DOI: 10.1002/elps.11501601175

31 O'Farrell PH: High resolution two-dimensional electrophoresis of proteins. J Biol Chem 250(10): 4007-4021, 1975. PMID: 236308 .

32 Higareda-Almaraz JC, Enríquez-Gasca Mdel R, Hernández-Ortiz M, Resendis-Antonio O and Encarnación-Guevara S: Proteomic patterns of cervical cancer cell lines, a network perspective. BMC Syst Biol 5: 96, 2011. PMID: 21696634. DOI: 10.1186/1752-0509-5-96

33 UniProt Consortium.: UniProt: a worldwide hub of protein knowledge. Nucleic Acids Res 47(D1): D506-D515, 2019. PMID: 30395287. DOI: 10.1093/nar/gky1049

34 Orchard S, Ammari M, Aranda B, Breuza L, Briganti L, Broackes-carter F, Campbell N, Chavali G, Chen C, Del-toro N, Duesbury M, Dumousseau M, Galeota E, Hinz U, Iannuccelli M, Jagannathan S, Jimenez R, Khadake J, Lagreid A, Licata L, Lovering R, Meldal B, Melidoni A, Milagros M, Peluso D, Perfetto L, Porras P, Raghunath A, Ricard-blum S, Roechert B, Stutz A, Tognolli M, Van roey K, Cesareni G and Hermjakob H: The MIntAct project-IntAct as a common curation platform for 11 molecular interaction databases. Nucleic Acids Research 42(D1): D358-D363, 2019. DOI: 10.1093/nar/gkt1115

35 Jassal B, Matthews L, Viteri G, Gong C, Lorente P, Fabregat A, Sidiropoulos K, Cook J, Gillespie M, Haw R, Loney F, May B, Milacic M, Rothfels K, Sevilla C, Shamovsky V, Shorser S, Varusai T, Weiser J, Wu G, Stein L, Hermjakob $\mathrm{H}$ and D'Eustachio P: The reactome pathway knowledgebase. Nucleic Acids Res 48(D1): D498-D503, 2020. PMID: 31691815. DOI: 10.1093/nar/gkz1031

36 Stelzer G, Rosen N, Plaschkes I, Zimmerman S, Twik M, Fishilevich S, Stein TI, Nudel R, Lieder I, Mazor Y, Kaplan S, Dahary D, Warshawsky D, Guan-Golan Y, Kohn A, Rappaport N, Safran M and Lancet D: The GeneCards Suite: From gene data mining to disease genome sequence analyses. Curr Protoc Bioinformatics 54: 1.30.1-1.30.33, 2016. PMID: 27322403. DOI: $10.1002 /$ cpbi.5

37 Shannon P, Markiel A, Ozier O, Baliga NS, Wang JT, Ramage D, Amin N, Schwikowski B and Ideker T: Cytoscape: A software environment for integrated models of biomolecular interaction networks. Genome Res 13(11): 2498-2504, 2003. PMID: 14597658. DOI: $10.1101 /$ gr.1239303

38 Szklarczyk D, Gable AL, Lyon D, Junge A, Wyder S, HuertaCepas J, Simonovic M, Doncheva NT, Morris JH, Bork P, Jensen LJ and Mering CV: STRING v11: Protein-protein association networks with increased coverage, supporting functional discovery in genome-wide experimental datasets. Nucleic Acids Res 47(D1): D607-D613, 2019. PMID: 30476243. DOI: 10.1093/nar/gky1131

39 Uhlen M, Zhang C, Lee S, Sjöstedt E, Fagerberg L, Bidkhori G, Benfeitas R, Arif M, Liu Z, Edfors F, Sanli K, von Feilitzen K, Oksvold P, Lundberg E, Hober S, Nilsson P, Mattsson J, Schwenk JM, Brunnström H, Glimelius B, Sjöblom T, Edqvist PH, Djureinovic D, Micke P, Lindskog C, Mardinoglu A and Ponten F: A pathology atlas of the human cancer transcriptome. Science 357(6352): 2017. PMID: 28818916. DOI: 10.1126/ science.aan 2507

40 Smith JS, Lindsay L, Hoots B, Keys J, Franceschi S, Winer R and Clifford GM: Human papillomavirus type distribution in invasive cervical cancer and high-grade cervical lesions: A meta- 
analysis update. Int J Cancer 121(3): 621-632, 2007. PMID: 17405118. DOI: $10.1002 / \mathrm{ijc} .22527$

41 Psyrri A and DiMaio D: Human papillomavirus in cervical and head-and-neck cancer. Nat Clin Pract Oncol 5(1): 24-31, 2008. PMID: 18097454. DOI: 10.1038/ncponc0984

42 Howard JD and Chung CH: Biology of human papillomavirusrelated oropharyngeal cancer. Semin Radiat Oncol 22(3): 187-193, 2012. PMID: 22687942. DOI: 10.1016/j.semradonc.2012.03.002

43 De la garza-ramos M, Urrutia-baca V, Urbina-rios C, Garcíarobayo D, Tamez-guerra P and Gomez-flores R: Prevalence of human papillomavirus in the oral cavity of an indigenous community from Southwest México. Infection, Genetics and Evolution 83: 104283, 2020. DOI: 10.1016/j.meegid.2020.104283

44 Hang D, Yin Y, Han J, Jiang J, Ma H, Xie S, Feng X, Zhang K, Hu Z, Shen H, Clifford GM, Dai M and Li N: Analysis of human papillomavirus 16 variants and risk for cervical cancer in Chinese population. Virology 488: 156-161, 2016. PMID: 26650690. DOI: 10.1016/j.virol.2015.11.016

45 Goodwin EC and DiMaio D: Repression of human papillomavirus oncogenes in HeLa cervical carcinoma cells causes the orderly reactivation of dormant tumor suppressor pathways. Proc Natl Acad Sci USA 97(23): 12513-12518, 2000. PMID: 11070078. DOI: $10.1073 /$ pnas.97.23.12513

46 Prokopczyk B, Sinha I, Trushin N, Freeman WM, El-Bayoumy K. Gene expression profiles in HPV-immortalized human cervical cells treated with the nicotine-derived carcinogen 4(methylnitrosamino)-1-(3-pyridyl)-1-butanone. Chem Biol Interact. 177(3): 173-180, 2009. PMID: 19038236. DOI: 10.1016/j.cbi.2008.10.051. Epub 2008 Nov 6.

47 Ganguly P and Ganguly N: Transcriptomic analyses of genes differentially expressed by high-risk and low-risk human papilloma virus E6 oncoproteins. Virusdisease 26(3): 105-116, 2015. PMID: 26396976. DOI: 10.1007/s13337-015-0259-7

48 Pang LY and Argyle D: Cancer stem cells and telomerase as potential biomarkers in veterinary oncology. Vet J 185(1): 15-22, 2010. PMID: 20580998. DOI: 10.1016/j.tvj1.2010.04.008

49 Douville J, Beaulieu R and Balicki D: ALDH1 as a functional marker of cancer stem and progenitor cells. Stem Cells Dev 18(1): 17-25, 2009. PMID: 18573038. DOI: 10.1089/scd.2008.0055

50 Yao J, Jin Q, Wang XD, Zhu HJ and Ni QC: Aldehyde dehydrogenase 1 expression is correlated with poor prognosis in breast cancer. Medicine (Baltimore) 96(25): e7171, 2017. PMID: 28640095. DOI: 10.1097/MD.0000000000007171

51 Zhu B, Zhou L, Yu L, Wu S, Song W, Gong X and Wang D: Evaluation of the correlation of vasculogenic mimicry, ALDH1, KAI1 and microvessel density in the prediction of metastasis and prognosis in colorectal carcinoma. BMC Surg 17(1): 47, 2017. PMID: 28431527. DOI: 10.1186/s12893-017-0246-6

52 Januchowski R, Wojtowicz K, Sterzyfska K, Sosifska P, Andrzejewska M, Zawierucha P, Nowicki M and Zabel M: Inhibition of ALDH1A1 activity decreases expression of drug transporters and reduces chemotherapy resistance in ovarian cancer cell lines. Int J Biochem Cell Biol 78: 248-259, 2016. PMID: 27443528. DOI: 10.1016/j.biocel.2016.07.017

53 Kwiatkowska-Borowczyk E, Czerwińska P, Mackiewicz J, Gryska K, Kazimierczak U, Tomela K, Przybyła A, Kozłowska AK, Galus Ł, Kwinta Ł, Dondajewska E, Gąbka-Buszek A, Żakowska M and Mackiewicz A: Whole cell melanoma vaccine genetically modified to stem cells like phenotype generates specific immune responses to ALDH1A1 and long-term survival in advanced melanoma patients. Oncoimmunology 7(11): e1509821, 2018. PMID: 30377573. DOI: 10.1080/2162402X. 2018.1509821

54 Xu T, Liu S, Ma T, Jia Z, Zhang Z and Wang A: Aldehyde dehydrogenase 2 protects against oxidative stress associated with pulmonary arterial hypertension. Redox Biol 11: 286-296, 2017. PMID: 28030785. DOI: 10.1016/j.redox.2016.12.019

55 Clark D and Palle K: Aldehyde dehydrogenases in cancer stem cells: potential as therapeutic targets. Annals of Translational Medicine 4(24): 518-518, 2017. DOI: 10.21037/atm.2016.11.82

56 Januchowski R, Wojtowicz K, Zabel M. The role of aldehyde dehydrogenase $(\mathrm{ALDH})$ in cancer drug resistance. Biomed Pharmacother. 2013 Sep;67(7):669-80. doi: 10.1016/j.biopha. 2013.04.005. Epub 2013 May 9. PMID: 23721823.

57 Singh S, Brocker C, Koppaka V, Chen Y, Jackson B, Matsumoto A, Thompson D and Vasiliou V: Aldehyde dehydrogenases in cellular responses to oxidative/electrophilicstress. Free Radical Biology and Medicine 56: 89-101, 2020. DOI: 10.1016/ j.freeradbiomed.2012.11.010

58 Vassalli G: Aldehyde Dehydrogenases: Not just markers, but functional regulators of stem cells. Stem Cells Int 2019: 3904645, 2019. PMID: 30733805. DOI: 10.1155/2019/3904645

59 Nwani NG, Condello S, Wang Y, Swetzig WM, Barber E, Hurley T and Matei D: A novel ALDH1A1 inhibitor targets cells with stem cell characteristics in ovarian cancer. Cancers (Basel) 11(4): 2019. PMID: 30965686. DOI: 10.3390/cancers 11040502

60 Tomita H, Tanaka K, Tanaka $\mathrm{T}$ and Hara A: Aldehyde dehydrogenase $1 \mathrm{~A} 1$ in stem cells and cancer. Oncotarget 7(10): 11018-11032, 2016. PMID: 26783961. DOI: 10.18632/ oncotarget.6920

61 Miura T, Mattson MP and Rao MS: Cellular lifespan and senescence signaling in embryonic stem cells. Aging Cell 3(6): 333-343, 2004. PMID: 15569350. DOI: 10.1111/j.14749728.2004.00134.x

62 Noormohammadi A, Khodakarami A, Gutierrez-Garcia R, Lee HJ, Koyuncu S, König T, Schindler C, Saez I, Fatima A, Dieterich C and Vilchez D: Somatic increase of CCT8 mimics proteostasis of human pluripotent stem cells and extends C. elegans lifespan. Nat Commun 7: 13649, 2016. PMID: 27892468. DOI: 10.1038/ncomms 13649

63 Showalter AE, Martini AC, Nierenberg D, Hosang K, Fahmi NA, Gopalan P, Khaled AS, Zhang W and Khaled AR: Investigating Chaperonin-Containing TCP-1 subunit 2 as an essential component of the chaperonin complex for tumorigenesis. Sci Rep 10(1): 798, 2020. PMID: 31964905. DOI: 10.1038/s41598-020-57602-w

64 Horwich AL, Fenton WA, Chapman E and Farr GW: Two families of chaperonin: Physiology and mechanism. Annu Rev Cell Dev Biol 23: 115-145, 2007. PMID: 17489689. DOI: 10.1146/annurev.cellbio.23.090506.123555

65 Siegers K, Bölter B, Schwarz JP, Böttcher UM, Guha S, Hartl FU. TRiC/CCT cooperates with different upstream chaperones in the folding of distinct protein classes. EMBO J. 2003 Oct 1;22(19):5230-40. doi: 10.1093/emboj/cdg483. Retraction in: Siegers K, Bölter B, Schwarz JP, Böttcher UM, Guha S, Hartl FU. EMBO J. 2008 Jan 9; 27(1):301. PMID: 14517260.

66 Sternlicht H, Farr GW, Sternlicht ML, Driscoll JK, Willison K and Yaffe MB: The t-complex polypeptide 1 complex is a chaperonin for tubulin and actin in vivo. Proc Natl Acad Sci USA 90(20): 9422-9426, 1993. PMID: 8105476. DOI: 10.1073/ pnas.90.20.9422 
67 Kubota H, Hynes G and Willison K: The eighth Cct gene, Cctq, encoding the theta subunit of the cytosolic chaperonin containing TCP-1. Gene 154(2): 231-236, 1995. PMID: 7890169. DOI: 10.1016/0378-1119(94)00880-2

68 Willison KR, Hynes G, Davies P, Goldsborough A and Lewis VA: Expression of three t-complex genes, Tcp-1, D17Leh117c3, and D17Leh66, in purified murine spermatogenic cell populations. Genet Res 56(2-3): 193-201, 1990. PMID: 2272510. DOI: 10.1017/s0016672300035291

69 Yang X, Ren H, Shao Y, Sun Y, Zhang L, Li H, Zhang X, Yang $\mathrm{X}, \mathrm{Yu} \mathrm{W}$ and $\mathrm{Fu} \mathrm{J}$ : Chaperonin-containing T-complex protein 1 subunit 8 promotes cell migration and invasion in human esophageal squamous cell carcinoma by regulating $\alpha$-actin and $\beta$-tubulin expression. Int J Oncol 52(6): 2021-2030, 2018. PMID: 29620162. DOI: 10.3892/ijo.2018.4335

70 Huang X, Wang X, Cheng C, Cai J, He S, Wang H, Liu F, Zhu $\mathrm{C}$, Ding $\mathrm{Z}$, Huang $\mathrm{X}$, Zhang $\mathrm{T}$ and Zhang $\mathrm{Y}$ : Chaperonin containing TCP1, subunit 8 (CCT8) is upregulated in hepatocellular carcinoma and promotes HCC proliferation. APMIS 122(11): 1070-1079, 2014. PMID: 24862099. DOI: 10.1111/apm.12258
71 Yin H, Miao X, Wu Y, Wei Y, Zong G, Yang S, Chen X, Zheng G, Zhu X, Guo Y, Li C, Chen Y, Wang Y and He S: The role of the Chaperonin containing t-complex polypeptide 1 , subunit 8 (CCT8) in B-cell non-Hodgkin's lymphoma. Leuk Res 45: 5967, 2016. PMID: 27101149. DOI: 10.1016/j.leukres.2016.04.010

72 Wurlitzer M, Möckelmann N, Kriegs M, Vens M, Omidi M, Hoffer K, Bargen CV, Möller-Koop C, Witt M, Droste C, Oetting A, Petersen H, Busch CJ, Münscher A, Schlüter H, Clauditz TS and Rieckmann T: Mass Spectrometric Comparison of HPV-Positive and HPV-Negative Oropharyngeal Cancer. Cancers (Basel) 12(6): 2020. PMID: 32545200. DOI: $10.3390 /$ cancers 12061531
Received January 9, 2021

Revised February 19, 2021

Accepted February 23, 2021 